\title{
Anakinra as a diagnostic challenge and treatment option for systemic autoinflammatory disorders of undefined genetic cause
}

\author{
S Harrison', S Nizam², M McDermot', D McGonagle', S Savic ${ }^{1,3^{*}}$ \\ From 8th International Congress of Familial Mediterranean Fever and Systemic Autoinflammatory Diseases \\ Dresden, Germany. 30 September - 3 October 2015
}

\section{Background}

Diverse monogenic autoinflammatory diseases share responsiveness to interleukin (IL)-1 blockade. This study explored the utility of anakinra (an IL-1 receptor antagonist) as a treatment option for clinically heterogeneous systemic inflammatory disease with autoinflammatory presentations where a genetic cause was not defined.

\section{Methods}

A total of ten adult cases with ongoing inflammatory episodes, where alternative diagnoses, including malignancy and infection, were evaluated. Genetic screening was also performed to exclude known genetic causes of autoinflammatory disorders (e.g. cryopyrin-associated periodic syndromes (CAPS), tumour necrosis factor receptorassociated periodic syndrome (TRAPS), etc.)

\section{Results}

All patients had presentations that were atypical of recognised autoinflammatory disorders and all were negative on genetic screening. Eight of ten cases showed rapid responsiveness to anakinra with the ability to subsequently taper alternative immunosuppression. Good responses to anakinra were maintained with inadvertent drug discontinuation being linked to disease flares.

\section{Conclusions}

The spectrum of poorly defined clinical and genetic autoinflammatory disorders that show responsiveness to anakinra is considerable. In fact, responsiveness to anakinra appears

'University of Leeds, Institute of Rheumatic and Musculoskeletal Medicine, Leeds, UK

Full list of author information is available at the end of the article to be useful in diagnosis given the characteristically rapid onset of efficacy and symptomatic improvement.

\section{Authors' details}

'University of Leeds, Institute of Rheumatic and Musculoskeletal Medicine, Leeds, UK. ${ }^{2}$ Pinderfields Hospital, Department of Rheumatology, Wakefield, UK. ${ }^{3}$ Leeds Teaching Hospitals NHS Trust, Clinical Immunology and Allergy, Leeds, UK.

Published: 28 September 2015

doi:10.1186/1546-0096-13-S1-P189

Cite this article as: Harrison et al:: Anakinra as a diagnostic challenge and treatment option for systemic autoinflammatory disorders of undefined genetic cause. Pediatric Rheumatology 2015 13(Suppl 1):P189.
Submit your next manuscript to BioMed Central and take full advantage of:

- Convenient online submission

- Thorough peer review

- No space constraints or color figure charges

- Immediate publication on acceptance

- Inclusion in PubMed, CAS, Scopus and Google Scholar

- Research which is freely available for redistribution
() Biomed Central 